\title{
Small Cell Cancer of the Parotid Gland
}

Hassan Almubarak (1)

Awad Alsamghan (2)

Mohammed Abadi Al-Saleem (2)

Eisa Yazeed Ghazwani (3)

Safar Abadi Al-Saleem (2)

(1) Division of Radiology, Department of Internal Medicine, College of Medicine, King Khalid University, Abha, Kingdom of Saudi Arabia

(2) Department of Family \& Community Medicine, College of Medicine, King Khalid University, Abha, Kingdom of Saudi Arabia

(3) Department of Family \& Community Medicine, Faculty of Medicine, Najran University, Najran, Kingdom of Saudi Arabia

Corresponding author:

Dr. Awad S. Alsamghan

Department of Family \& Community Medicine,

College of Medicine, King Khalid University, Abha,

Kingdom of Saudi Arabia

Email: awadalsamghan@gmail.com

Received September 2020. Accepted October 2020. Published December 1, 2020.

Please cite this article as: Hassan Almubarak et al. Small Cell Cancer of the Parotid Gland. Middle East J Intern Med 2020; $13(3)$ : 3-6. DOI: 10.5742/MEJIM2020.93791

\section{ABSTRACT}

Salivary gland small cell carcinomas $(\mathrm{SmCC})$ are extremely rare and metastasis from lung only being reported in select case studies. This is a case of parotid gland $\mathrm{SmCC}$ and lung SmCC. The pulmonary mass may represent metastasis from the parotid tumor. However, a new lung primary could not be excluded. A synchronous primary lung SmCC appears to be more likely.

\section{Introduction}

Salivary gland small cell carcinomas $(\mathrm{SmCC})$ are sporadic with primaries accounting for less than $1 \%$ of salivary gland tumors with bad prognosis [1,2] and metastasis from lung is only being reported in select case studies [3]. Often these are classified into neuroendocrine or ductal carcinomas [4]. This is a case of parotid gland SmCC and lung SmCC.

\section{Case Report}

A 73-year-old gentleman presented with a lump over his right parotid gland region, which had grown over 10 months. The initial fine needle aspiration (FNA) at 4 months was negative. However, a second FNA showed atypical small cells and abundant lymphocytes, consistent with SmCC. On subsequent staging FDG PET, a soft tissue mass of $3 \mathrm{~cm}$ within the right parotid gland was identified with intense FDG uptake (Figure 1). 


\section{Figure 1}

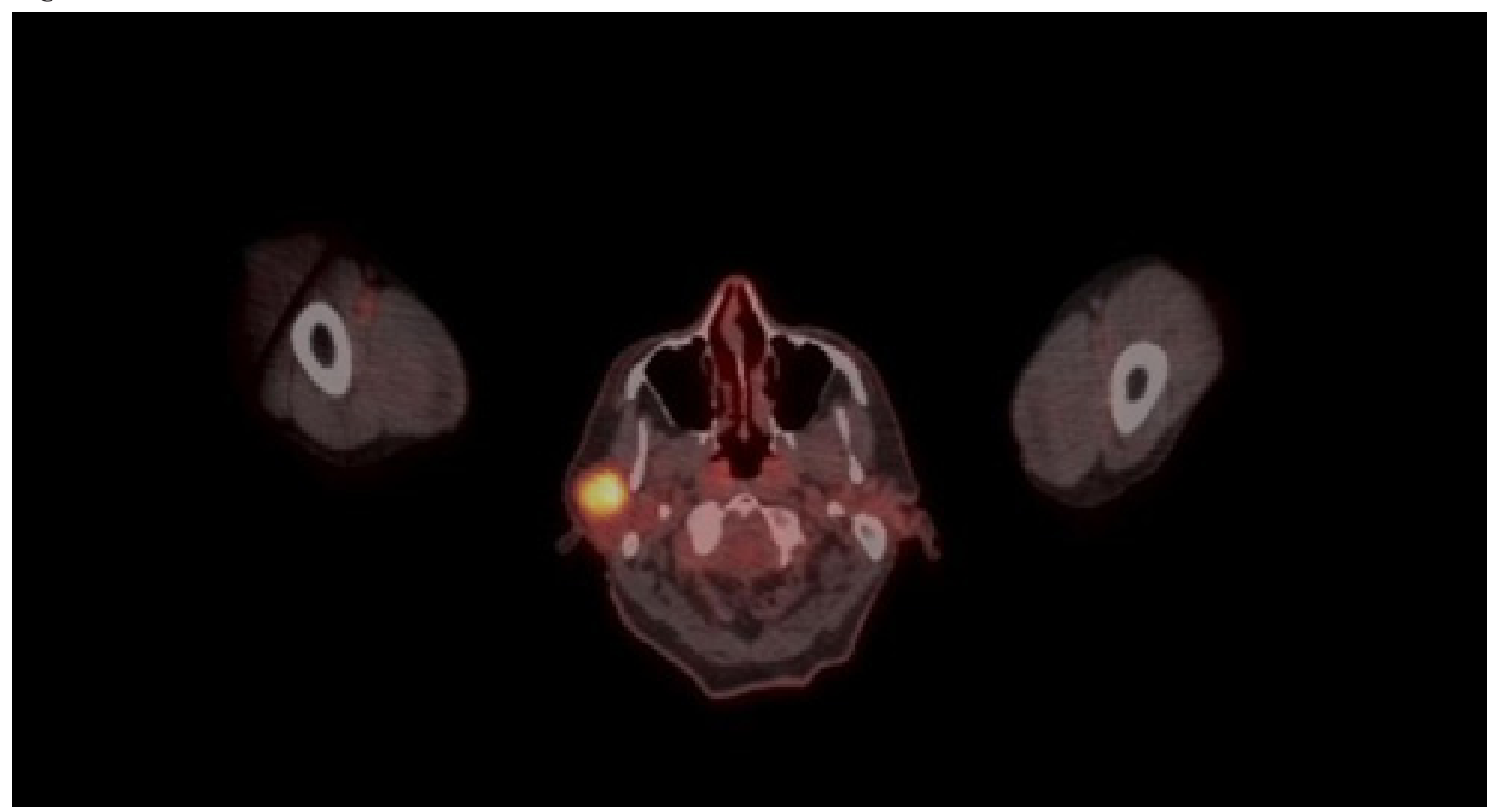

The patient was a former heavy smoker with a 110 pack-year history and a positive family history for lung cancer and on FDG PET staging, a highly hypermetabolic mass of $7 \mathrm{~cm}$ was also identified in the right lung (Figure 2).

\section{Figure 2}

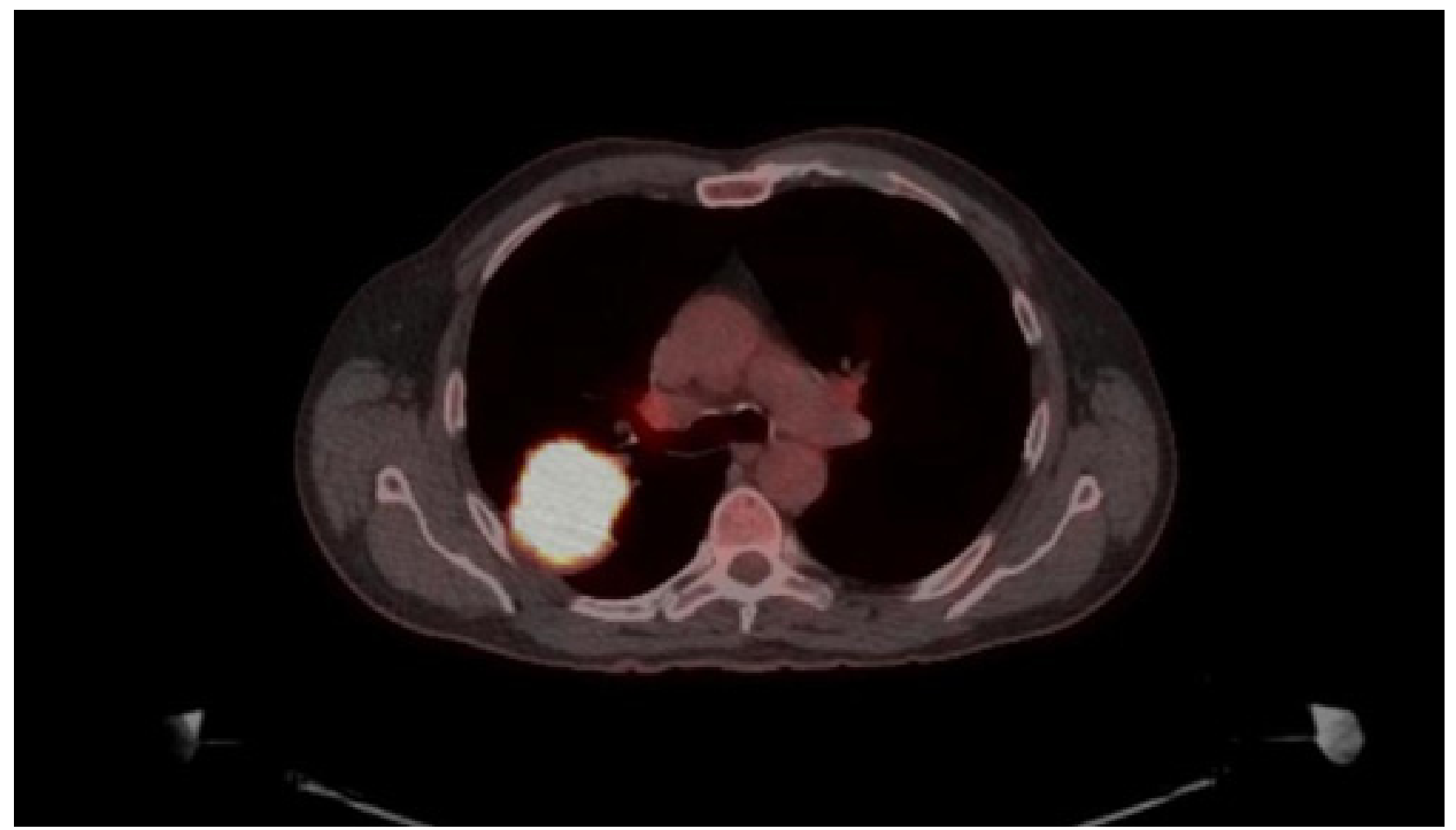


The lung biopsy showed similar histological features to the parotid. Based on the pathologist's opinion, the lung mass may represent a metastasis from the parotid tumor. However, a new lung primary could not be totally excluded. Maximum-intensity projection (MIP) 18F-FDG PET of the parotid gland and lung FDG activity shows similar high metabolic activities in both right parotid and right lung mass (Figure 3).

\section{Figure 3}

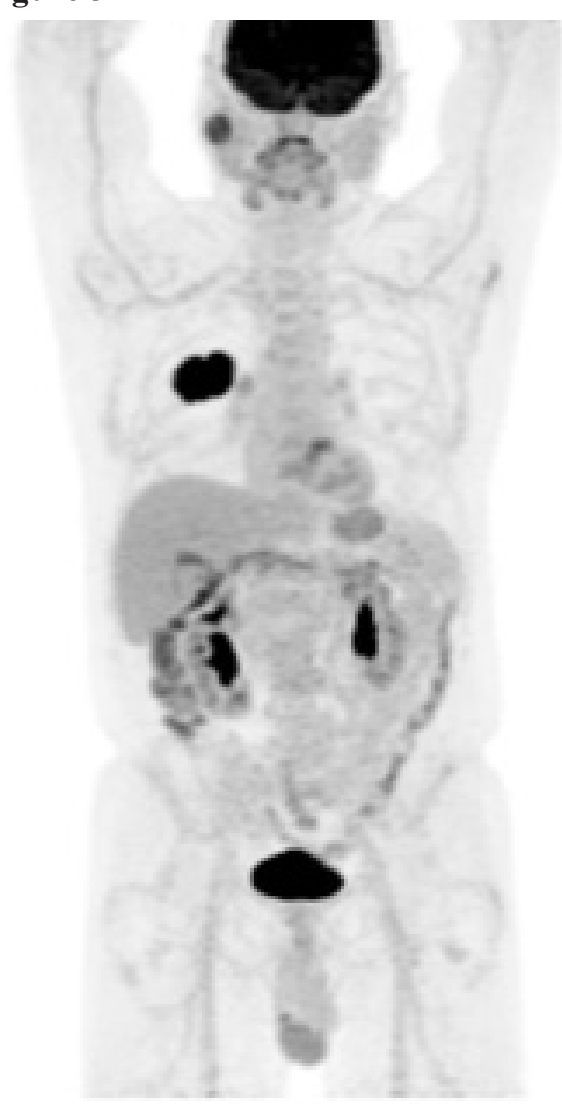

\section{Discussion}

SmCC of the parotid gland has only been presented in select cases and typically presents in the lung; since the parotid is an unlikely area for a SmCC primary [5], it is important to exclude the possibility of a metastases.

Based on the limited case reports of this malignancy, patients generally present with a progressively enlarging neck mass followed by FNA biopsy and subsequent metastatic work-up.

Based on the case reports, SmCC is typically highly FDG avid. The FDG metabolic imaging parameters can differentiate benign and malignant tumor uptake in parotid glands. There are four levels of FDG uptake in parotid glands: normal physiologic uptake, increased diffuse uptake, benign tumor uptake, and malignant tumor uptake. The FDG metabolic imaging parameters can differentiate benign and malignant tumor uptake in parotid glands [6].
On MRI images, the tumor typically demonstrates circumscribed and heterogeneous enhancement on gadolinium-enhanced T1-weighted images. Specific signs predictive of malignancy are T2 hypointensity of the parotid tumor, ill-defined margins, diffuse growth, infiltration of subcutaneous tissue, and lymphadenopathy [7]. Tumor size appears to be the most important prognostic factor [8].

As this patient demonstrated a second lesion in the lung it is difficult to determine the patient's specific prognosis. Small cell lung cancer (SCLC) is staged into two categories; limited stage indicates SCLC is only located on one side of the chest and can be treated by radiation and chemotherapy and rarely, by surgery. While the other stage, termed extensive stage, means that SCLC has spread throughout the lung to the lymph nodes or has metastasised to other parts of the body [9].

It is helpful to note that the prognosis of primary SmCC of salivary glands appears to be more favorable than those found in other areas with a 5 -year survival of $46 \%$ (compared to lung with $31 \%$ or less obviously based on the stage) [10]. Ultimately, the treatment consists of a combination of surgery followed by chemotherapy and radiation [11]. 


\section{Conclusions}

Small cell carcinoma is primarily a pulmonary neoplasm that rarely arises in extrapulmonary sites, including salivary glands of the head and neck. Our case is a 73-year-old man who presented with right parotid SmCC and mass in the right lung of similar histological features to the parotid lesion. The pulmonary mass may represent a metastasis from the parotid tumour, however a new lung primary could not be excluded. Based on the intensity of the parotid gland and lung FDG activity, a primary lung SmCC as a synchronous cancer appears to be more likely. We still need more cases and may be case series similar to this report to have a better understanding.

\section{References}

1. Altinay, S., Firat, P., Yalcin, S., Taskin,: Primary small cell carcinoma of the parotid: Fine needle aspiration and immunohistochemical features of a neuroendocrine variant. Journal of Cytology. 33:34-36.

2. Koss LG, Spiro RH, Hajdu S. Small cell (oat cell) carcinoma of minor salivary gland origin. Cancer. 1972;30:73741

3. Baca, J.M., Chiara, et al.: Small-Cell Carcinoma of the Parotid Gland. Journal of Clinical Oncology. 29:34-36.

4. Kraemer, B.B., MacKay, B., Batsakis, J.G.: Small Cell Carcinomas of the Parotid Gland. Cancer Small. 52:2115-2121. 10.1002/1097-0142(19831201)52:11<2115::aidcncr2820521124>3.0.co; $2-\mathrm{z}$

5. Kim JH, Lee SH, Park J, Kim HY, Lee SI, Nam EM, et al. Extrapulmonary small-cell carcinoma: A single-institution experience. Jpn J Clin Oncol. 2004;34:250-4.

6. David Hadiprodjo, Timothy Ryan, Minh-Tam Truong, Gustavo Mercier, and Rathan M. Subramaniam: American Journal of Roentgenology. 2012;198: W185-W190. 10.2214/ AJR.11.7172

7. A. Christe, C. Waldherr, R. Hallett, P. Zbaeren and H. Thoeny: American Journal of Neuroradiology August 2011, 32 (7) 1202-1207

8. Nagao T, Gaffey TA, Olsen KD, Serizawa H, Lewis JE. Small cell carcinoma of the major salivary glands: Clinicopathologic study with emphasis on cytokeratin 20 immunoreactivity and clinical outcome. Am J Surg Pathol. 2004;28:76270.

9. Jan P. Van Meerbeeck; Dean A. Fennell; Dirk K.M. De Ruysscher: Small-cell lung cancer. The Lancet. 2011, 9804:1741-1755. doi.org/10.1016/S0140-6736(11)60165-7

10. Gnepp, D.R., Corio, R.L., Brannon, R.B.: Small Cell Carcinoma of the Major Salivary Glands. Cancer. 58:705-714. 10.1002/1097-0142(19860801)58:3<705::aidcncr2820580318>3.0.co;2-t.

11. Henke, A.C., Cooley, et al.: Fine-Needle Aspiration Cytology of Cell Carcinoma of the Parotid. Diagnostic Cytopathology. 25:126-129. 10.4103/0970-9371.175509 